\title{
Erratum to: Eicosapentaenoic and docosahexaenoic acids-rich fish oil supplementation attenuates strength loss and limited joint range of motion after eccentric contractions: a randomized, double-blind, placebo-controlled, parallel-group trial
}

\author{
Yosuke Tsuchiya $^{1} \cdot$ Kenichi Yanagimoto $^{2} \cdot$ Koichi Nakazato $^{3} \cdot$ Kohsuke Hayamizu $^{4}$. \\ Eisuke Ochi ${ }^{5}$
}

Published online: 21 July 2016

(C) Springer-Verlag Berlin Heidelberg 2016

\section{Erratum to: Eur J Appl Physiol (2016) 116: \\ 1179-1188}

DOI 10.1007/s00421-016-3373-3

The author would like to correct the following errors in the print publication of the article.

In page 1181, under the supplement section, the first sentence should read as follows:
The EPA group consumed eight $300 \mathrm{mg}$ EPA and DHArich fish oil softgel capsules (Nippon Suisan Kai-sha Ltd., Tokyo, Japan) per day (containing $600 \mathrm{mg}$ EPA and 260 mg DHA in a total of $2400 \mathrm{mg}$ )

Unfortunately, the Fig. 2 was published incorrectly in the original publication of the article. The correct figure is given below:

The online version of the original article can be found under doi:10.1007/s00421-016-3373-3.

\section{Eisuke Ochi}

ochi@hosei.ac.jp

1 Laboratory of Health and Sports Sciences, Meiji Gakuin University, Kanagawa, Japan

2 Human Life Science R\&D Center, Nippon Suisan Kaisha, Ltd., Tokyo, Japan

3 Graduate School of Health and Sport Science, Nippon Sport Science University, Tokyo, Japan

4 General Health Medical Center, Yokohama University of Pharmacy, Kanagawa, Japan

5 Faculty of Bioscience and Applied Chemistry, Hosei University, Tokyo, Japan 
1856

Eur J Appl Physiol (2016) 116:1855-1856

a

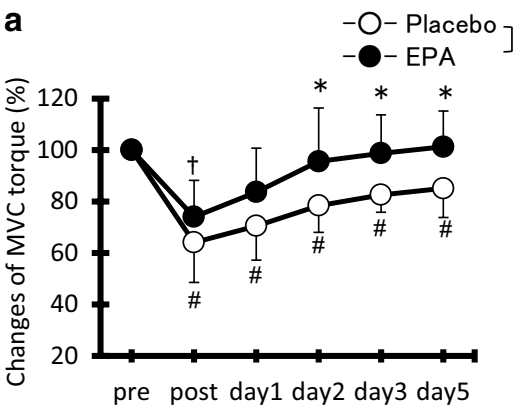

Time

d

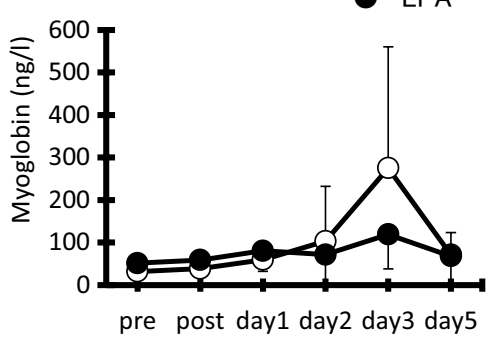

Time b
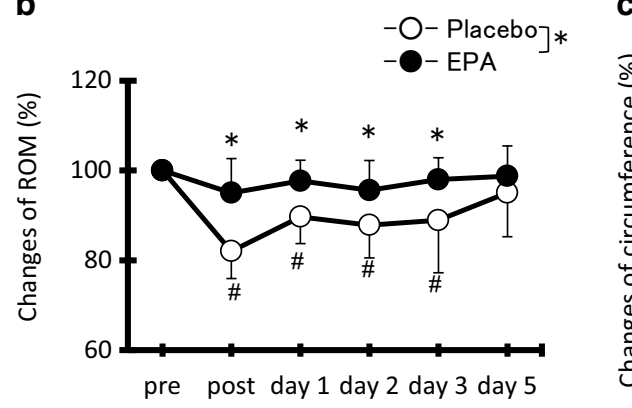

Time
C

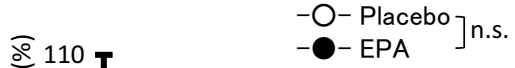

e
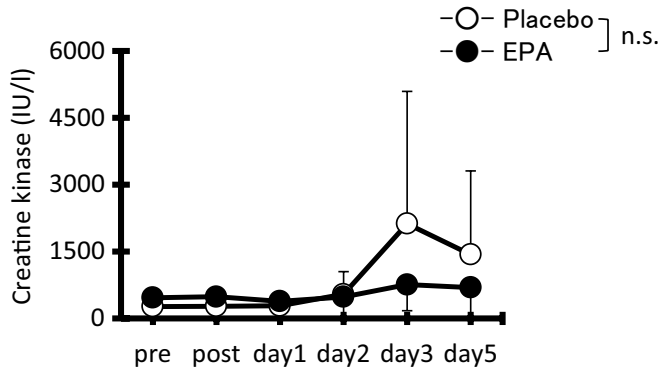

Time

Springer 